\title{
EVALUASI SISTEM PEMBERIAN AIR DAERAH IRIGASI KEDUNG PUTRI GUNA MENINGKATKAN INTENSITAS TANAM PADI
}

\author{
Isna Dinul Muiz ${ }^{1}$,Donny Harisuseno ${ }^{2}$, Runi Asmaranto ${ }^{2}$ \\ ${ }^{1)}$ Mahasiswa Magister Teknik Pengairan, Fakultas Teknik, Universitas Brawijaya, Malang, Jawa Timur, \\ ${ }^{2)}$ Dosen Jurusan Teknik Pengairan, Fakultas Teknik, Universitas Brawijaya, Malang, Jawa Timur, Indonesia \\ Email : isnamuiz@gmail.com
}

\begin{abstract}
ABSTRAK : Pada musim kemarau DI. Kedungputri mengalami kekeringan terutama pada daerah bagian hilir. Intensitas tanam pada kondisi eksistingpun kurang maksimal. Penelitian ini bertujuan untuk mengevaluasi intensitas tanam serta kebutuhn air irigasi di DI. Kedungputri. Dari hasil evaluasi, membuat rencana pola tanam dengan meningkatkan intensitas tanam padi serta menghitung kebutuhan air. Pada kajian ini menggunakan metode SCH (Stagnant Constant Head) dan metode SRI (Sytem of Rice Intensification). Intensitas tanam rerata padi gadu tidak ijin mencapai $73,05 \%$ pada tahun 2009-2014. Metode SRI lebih hemat air 68,55 \% - 75,45\% dibandingkan metode SCH. Apabila menggunakan metode $\mathrm{SCH}$, pemberian air secara gilir mencapai $83,33 \%$. Metode SRI dapat meningkatkan pendapatan petani dari hasil produksi gabah kering yaitu $180,52 \%$.
\end{abstract}

Kata Kunci : Daerah Irigasi Kedung Putri, intensitas tanam, metode SCH, metode SRI, pembagian air, rotasi.

\begin{abstract}
ABSTRAC : In dry season Kedungputri irrigation area often lack of water especially in areas downstream. Cropping intensity on existing conditions deemed less than the maximum.This study aimed to evaluate the intensity of cropping and requirement of irrigation in irrigation area of Kedungputri. From the results of evaluations that had been done, then created a new plan cropping patterns by increasing paddy cropping intensity and calculated water needs and water distribution when needed.In this study, the author used two methods of irrigation, i.e. SCH (Stagnant Constant Head) known by constant supply of water to crops and periodically supply of water to crop or known by SRI (System of Rice Intensification).Gadu paddy cultivation did not permit the average cropping intensity reached $73.05 \%$ in 2009-2014. The SRI method is $77.21 \%$ more water-efficient than the method SCH.The supplied of water in cultivation periodically reached $83.33 \%$.In addition to saving water, the SRI method can increase farmer's income from the production of dried grain which reached $150,82 \%$
\end{abstract}

Keywords : Irrigation area Kedungputri, cropping intensity, SCH method, SRI method, water distribution, rotation.

Pada dasarnya penduduk di Indonesia semakin hari bertambah pesat sehingga kebutuhan pangan masyarakat Indonesia juga bertambah, tetapi kondisi sumberdaya air semakin terbatas. Hal tersebut yang mejadi tantangan di sektor pertanian untuk meningkatkan produktivitas pangan di Indonesia.

Salah satu cara pemberian air irigasi dengan hemat namun menghasilkan produktivitas padi yang tinggi sehingga dapat memenuhi kebutuhan pangan masyarakat Indonesia adalah dengan budidaya padi metode SRI (System of Rice Intensification).

Kurang dari tujuh tahun yang lalu, SRI diketahui dan dilaksanakan hanya di Madagascar. Hingga kini terdapat 18 negara termasuk Indonesia yang telah memakai sistem ini mulai dari China hingga Peru, dengan ratarata panen hingga 15 ton/ha (Budi, 2007). Menurut Dede Rohmat (2007), kebutuhan air 
untuk metode SRI lebih hemat 60\%. Oleh sebab itu air dapat dimanfaatkan untuk kebutuhan lain seperti pemenuhan kebutuhan air baku.Irigasi untuk padi mempunyai tujuan untuk memberi air yang cukup dan stabil ke persawahan untuk menjamin produksi padi (Sosrodarsono, 1980:224).

Pada sistem pemberian air irigasi perlu adanya jadwal pembagian air irigasi bila diperlukan. Pemberian air secara rotasi dengan memperhatikan tingkat efektivitas air irigasi lebih condong ke arah penghematan penggunaan air irigasi sementara tetap menjaga tingkat produksi panen pada lahan-lahan yang bersangkutan.

Adapun permasalahan yang ada pada jaringan irigasi Kedungputri adalah:

1. Ketersediaan air semakin terbatas yang menyebabkan kekurangan air pada periodeperiode tertentu. Dari hasil survei awal di lapangan diperoleh bahwa pada perencanaan pemberian air dapat memenuhi kebutuhan air di lahan. Pada kenyataan di lapangan, pada musim kemarau terdapat lahan yang masih kekurangan air irigasi.

2. Di musim kemarau pada rencana tata tanam global (RTTG) sudah diatur untuk luas tanaman palawija dan padi, namun petani di Daerah Irigasi Kedung Putri tidak mengikuti RTTG yang telah dikeluarkan oleh Dinas Pengairan yaitu dengan tetap menanam padi tidak sesuai dari rencana.
3. Intensitas tanam padi yang kurang efektif. Hal tersebut terlihat pada rencana tata tanam terhadap kondisi eksisting tanam dari tahun 2009-2014

Tujuan dari penulisan ini adalah melakukan rencana tata tanam ulang dan sistem irigasi yang tepat dengan sistem pemberian air SCH (Stagnant Constant Head) dan SRI (System of Rice Intensification).Sehingga dapat diketahui metode manakah yang baik untuk meningkatkan intensitas tanam padi dengan pemaikaian air se-efektif mungkin.

\section{BAHAN DAN METODE}

\section{Lokasi Penelitian}

Daerah Irigasi Kedung Putri merupakan salah satu daerah irigasi di wilayah kerja UPTD Pengairan Pertambangan dan Energi Paron yang berada di Kecamatan Paron Kabupaten Ngawi Jawa timur.Secara geografis Kabupaten Ngawi terletak pada posisi $7^{\circ} 21^{\prime}-7^{\circ} 31^{\prime}$ Lintang Selatan dan $110^{\circ} 10^{\prime}-111^{\circ} 40^{\prime}$ Bujur Timur.Luas wilayah Kabupaten Ngawi adalah 1.295,58 $\mathrm{km}^{2}$, di mana sekitar 39 persen atau sekitar $504,76 \mathrm{~km}^{2}$ berupa lahan sawah.

D.I. Kedung Putri saat ini mengairi areal irigasi persawahan seluas 1869 Ha untuk 3 wilayah kecamatan yaitu Kecamatan Paron, Ngawi, dan Geneng

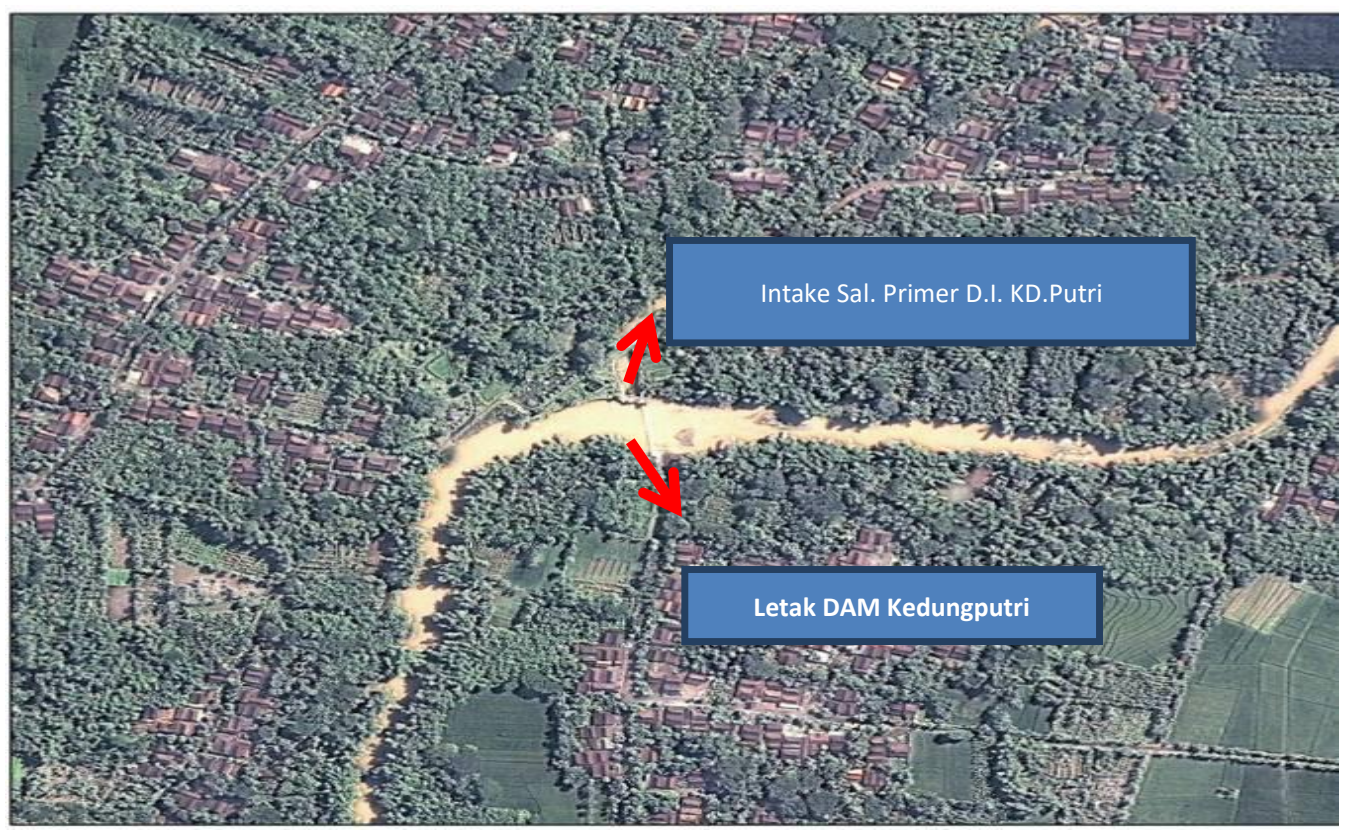

Gambar 1. DAM kedung Putri Sumber : Peta Citra Satelit 


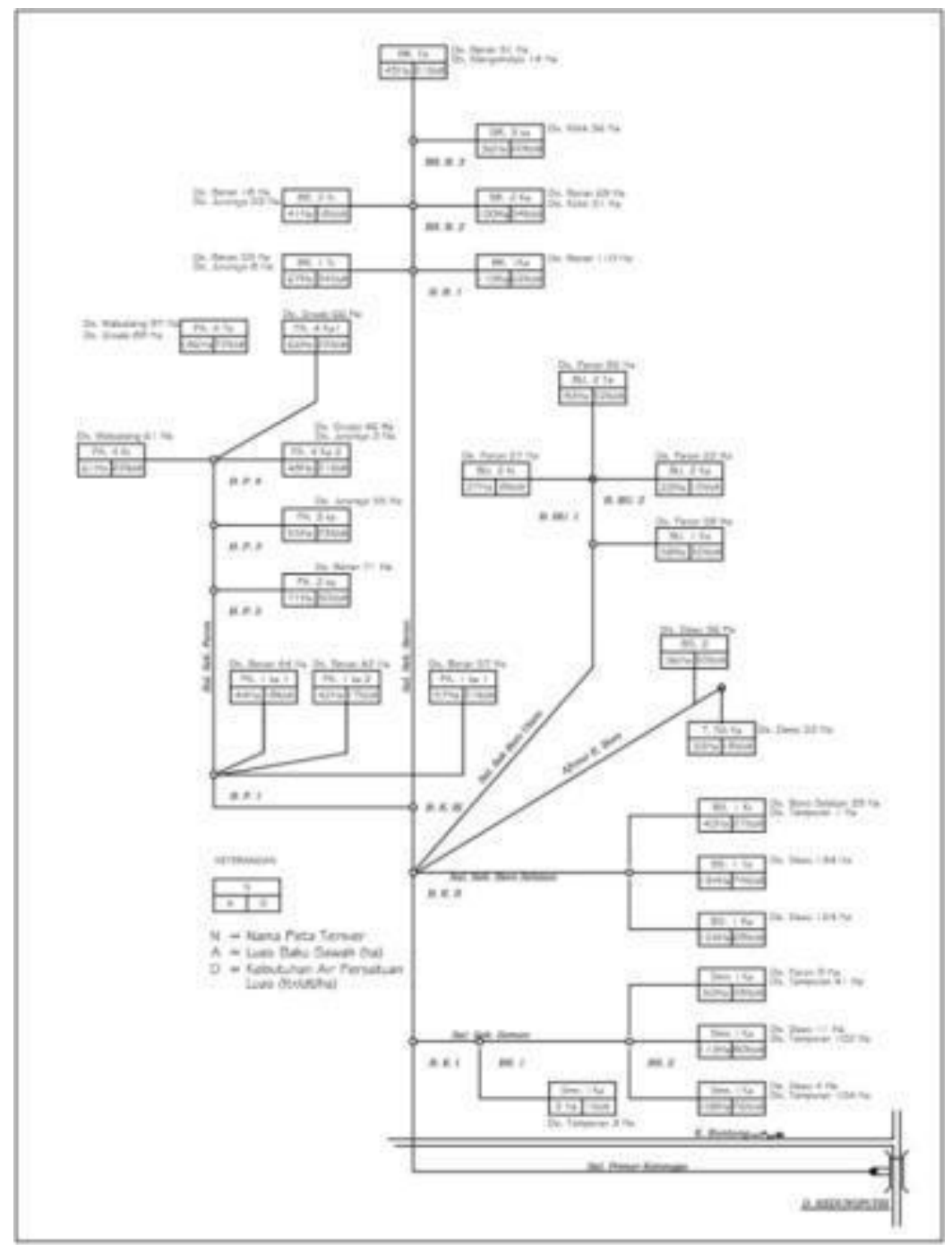

Gambar 2. Skema Jaringan Kedung Putri

Sumber :Dinas Pengairan kabupaten Ngawi

\section{Pengumpulan Data}

1. Data Debit

Data debit yang digunakan adalah data debit intake DAM Kedungputri rerata 10 harian, selama 5 tahun terakhir.

2. Data Irigasi Daerah Irigasi Daerah Irigasi Kedungputri
a. Skema jaringan irigasi yaitu untuk mengetahui luas baku sawah
b. Data jenis tanaman
c. Kebutuhan irigasi pada kondisi eksisting
d. Jadwal dan pola tanam
e. Luas area tanam
f. Data jenis tanah

\section{Metode Analisa}

Untuk penyelesaian penelitian ini dilakukan pengolahan data, baik data primer maupun data sekunder yang telah terkumpul. Adapun langkah-langkah dalam pengolahan data adalah sebagai berikut:

1. Perhitungan debit andalan menggunakan data debit intake Dam Kedung Putri. Dimana debit intake yang diperlukan adalah debit 5 tahun terakhir yaitu tahun 2009-2014. Debit andalan yang digunakan adalah debit andalan dengan metode Modus. Dimana modus adalah adalah variat yang terjadi pada frekuensi yang paling banyak. Debit andalan dengan metode modus lebih dipilih karena debit ini dihitung dari debit yang melalui pintu intake yang sudah diatur oleh manusia.

2. Mengevaluasi pola tanam kondisi eksisting untuk mengetahui intensitas tanam padi sehingga dapat digunakan sebagai acuan untuk merencanakan tata tanam yang baik. Untuk mengetahui kebutuhan air nyata dapat diketahui 
dengan cara sebagai berikut (Anonim, 1986):

Cara FPR dan LPR

$\mathrm{Q}_{\mathrm{keb}}=\mathrm{FPR} \times \mathrm{LPR}$

FPR = Faktor Palawija Relatif (ltr/det/ha.pol)

$\mathrm{Q} \quad=$ Debit yang mengalir di sungai (ltr/det)

LPR = Luas Palawija Relatif (ha.pol)

3. Membuat neraca air untuk menganalisa antara ketersediaan air dengan pemberian air.

4. Menganalisa cara pemberian air dan pembagian air irigasi berdasarkan keseimbangan air. Yaitu bila faktor $\mathrm{K}<1$ maka persediaan air kurang, sedangkan apabila faktor $\mathrm{K}=1$ maka air cukup.

5. Merencanakan pola tata tanam yang baru dengan beberapa alternatif untuk mendapatkan pola tanam yang paling efektif dengan harapan intensitas tanam padi meningkat, yaitu dengan alternatif SCH atau SRI.

6. Menghitung keuntungan dari hasil produksi tanam padi dengan metode SRI dan $\mathrm{SCH}$.

7. Membuat jadwal pembagian dan pemberian air irigasi pada masing-masing blok berdasarkan neraca air dengan pola tanam yang telah direncanakan.

8. Kesimpulan dan saran.

\section{Pemberian Air Irigasi}

Kebutuhan air tanaman dapat dihitung berdasarkan kebutuhan air di lapangan dan debit yang diperlukan pada pintu pemasukan yaitu (Anonim,1977):

$\mathrm{Q}_{1}=\frac{\mathrm{H} \times \mathrm{A}}{\mathrm{T}} \times 10.000$

$\mathrm{Q}_{2}=\frac{\mathrm{Q}_{1}}{86.400} \times \frac{1}{(1-\mathrm{L})}$

dimana :

$\mathrm{Q}_{1} \quad=$ kebutuhan harian air di

lapangan/petak sawah $\left(\mathrm{m}^{3} / \mathrm{hr}\right)$

$\mathrm{Q}_{2} \quad=$ kebutuhan harian air pada pintu pemasukan $\left(\mathrm{m}^{3} / \mathrm{det}\right)$

$\mathrm{H} \quad=$ tinggi genangan $(\mathrm{m})$

A $\quad=$ luas area sawah (ha)

$\mathrm{T}=$ interval pemberian air (hari)

L = kehilangan air di lapangan/petak sawah dan saluran $(\%)$
Irigasi Hemat Air Pada Budidaya Padi dengan Metode SRI (System rice of Intensifications)

Di Indonesia, ekstensifikasi berupa perluasan lahan sawah sudah mencapai titik jenuh, namun peluang intensifikasi masih terbuka lebar, salah satunya melalui System of Rice Intensification (SRI) (Mutakin, 2005). SRI merupakan aplikasi pertanian padi sawah, dengan menerapkan prinsip intensifikasi yang bersifat efektif, efisien, alamiah, dan ramah lingkungan (Rohmat, 2007).

Adapun keunggulan metode SRI (Mutakin, 2015):

1. Tanaman hemat air, Selama pertumbuhan dari mulai tanam sampai panen memberikan air max $2 \mathrm{~cm}$, paling baik macak-macak sekitar $5 \mathrm{~mm}$ dan ada periode pengeringan sampai tanah retak ( Irigasi terputus)

2. Hemat biaya, hanya butuh benih $5 \mathrm{~kg} / \mathrm{ha}$. Tidak memerlukan biaya pencabutan bibit, tidak memerlukan biaya pindah bibit, tenaga tanam kurang dll

3. Hemat waktu, ditanam bibit muda 5 - 12 hari setelah semai, dan waktu panen akan lebih awal

4. Produksi meningkat, di beberapa tempat mencapai 11 ton/ha

5. Ramah lingkungan, tidak menggunaan bahan kimia dan digantikan dengan mempergunakan pupuk organik (kompos, kandang dan Mikro-organisme Lokal), begitu juga penggunaan pestisida.

Adapun sistem pemberian air metode

SRIadalah sebagai berikut (Purba,2011):

1. Kondisi air dari macak-macak dibiarkan sampai retak rambut, kemudian diairi lagi sampai macak-macak. Kondisi ini dilakukan selama periode vegetatif dan pertumbuhan anakan (sampai dengan \pm 45 - 50 hari setelah tanam). Berdasarkan penelitian yang dilakukan oleh Balai Irigasi, kondisi retak rambut tercapai saat kadar air tanah mencapai $\pm 80 \%$ dari kadar air jenuh lapang (macak-macak).

2. Pada saat penyiangan, air irigasi diberikan sampai genangan $2 \mathrm{~cm}$ untuk memu-dahkan operasi alat penyiang. Setelah penyiangan selesai biasanya sawah dibiar-kan menjadi macak-macak dengan sendirinya

3. Pada waktu mulai fase pembungaan $( \pm 51-$ 70 hari setelah tanam) dan pengisian bulir sampai masak susu $( \pm 71-95$ hari setelah tanam), sawah diairi dan terus 
dipertahankan macak-macak. Fase ini tanaman padi sangat peka terhadap kekurangan air. Pemberian air secara intermittent juga dapat dilakukan dengan mengairi lahan sampai $2 \mathrm{~cm}$ dan lalu irigasi kembali diberikan saat retak rambut.

4. Pada fase pematangan bulir sampai panen ( $\pm 96-105$ hari setelah tanam), sawah dikeringkan. Pengeringan pada periode pematangan bertujuan untuk mempercepat dan menyeragamkan proses pematangan bulir padi

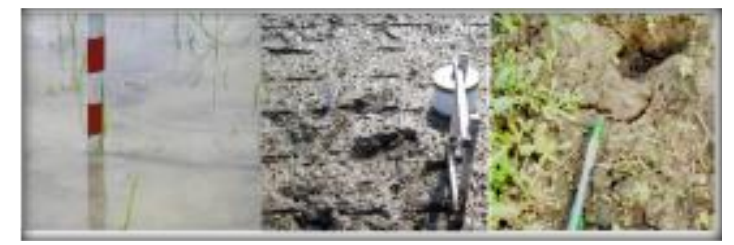

Gambar 3. Kondisi lahan saat genangan $2 \mathrm{~cm}$ (kiri) macak-macak (tengah) dan retak rambut (kanan)

Sumber : Purba, 2011

\section{HASIL DAN PEMBAHASAN}

\section{Perhitungan Debit Andalan DI. Kedung Putri}

Untuk memenuhi kebutuhan air irigasi D.I. Kedung Putri perlu diketahui berapa debit andalan yang tersedia. Untuk menghitung debit andalan yang tersedia diperlukan data debit intake DAM Kedung Putri (bukan debit sungai) setiap 10 hari selama 5 tahun (2009 2014) yang telah dicatat pada bangunan ukur debit.

Dalam memperhitungkan debit andalan, metode yang digunakan adalah dengan Modus, dimana dicari nilai yang sering muncul/terjadi.

Tabel. 1. Rekapitulasi Debit Andalan Menggunakan Modus Dalam liter/detik

\begin{tabular}{|c|c|c|c|c|c|}
\hline Bulan & Periode & Modus & Bulan & Periode & Modus \\
\hline \multirow{3}{*}{ Jan } & I & 789,75 & \multirow{3}{*}{ Jul } & I & 677,00 \\
\hline & II & 711,15 & & II & 572,80 \\
\hline & III & 744,17 & & III & 624,33 \\
\hline \multirow{3}{*}{ Feb } & I & 751,20 & \multirow{3}{*}{ Agust } & I & 593,92 \\
\hline & II & 885,00 & & II & 537,81 \\
\hline & III & 854,00 & & III & 577,88 \\
\hline \multirow{3}{*}{ Mar } & I & 767,25 & \multirow{3}{*}{ Sep } & I & 521,11 \\
\hline & II & 750,21 & & II & 552,78 \\
\hline & III & 885,43 & & III & 538,25 \\
\hline \multirow{3}{*}{ Apr } & I & 877,08 & \multirow{3}{*}{ Okt } & I & 533,33 \\
\hline & II & 881,63 & & II & 535,92 \\
\hline & III & 826,25 & & III & 581,50 \\
\hline \multirow{3}{*}{ Mei } & I & 873,00 & \multirow{3}{*}{ Nop } & I & 590,00 \\
\hline & II & 614,67 & & II & 748,67 \\
\hline & III & 609,50 & & III & 794,75 \\
\hline \multirow{3}{*}{ Jun } & I & 671,00 & \multirow{3}{*}{ Des } & I & 706,13 \\
\hline & II & 671,00 & & II & 839,60 \\
\hline & III & 680,93 & & III & 762,33 \\
\hline
\end{tabular}

Sumber : hasil perhitungan

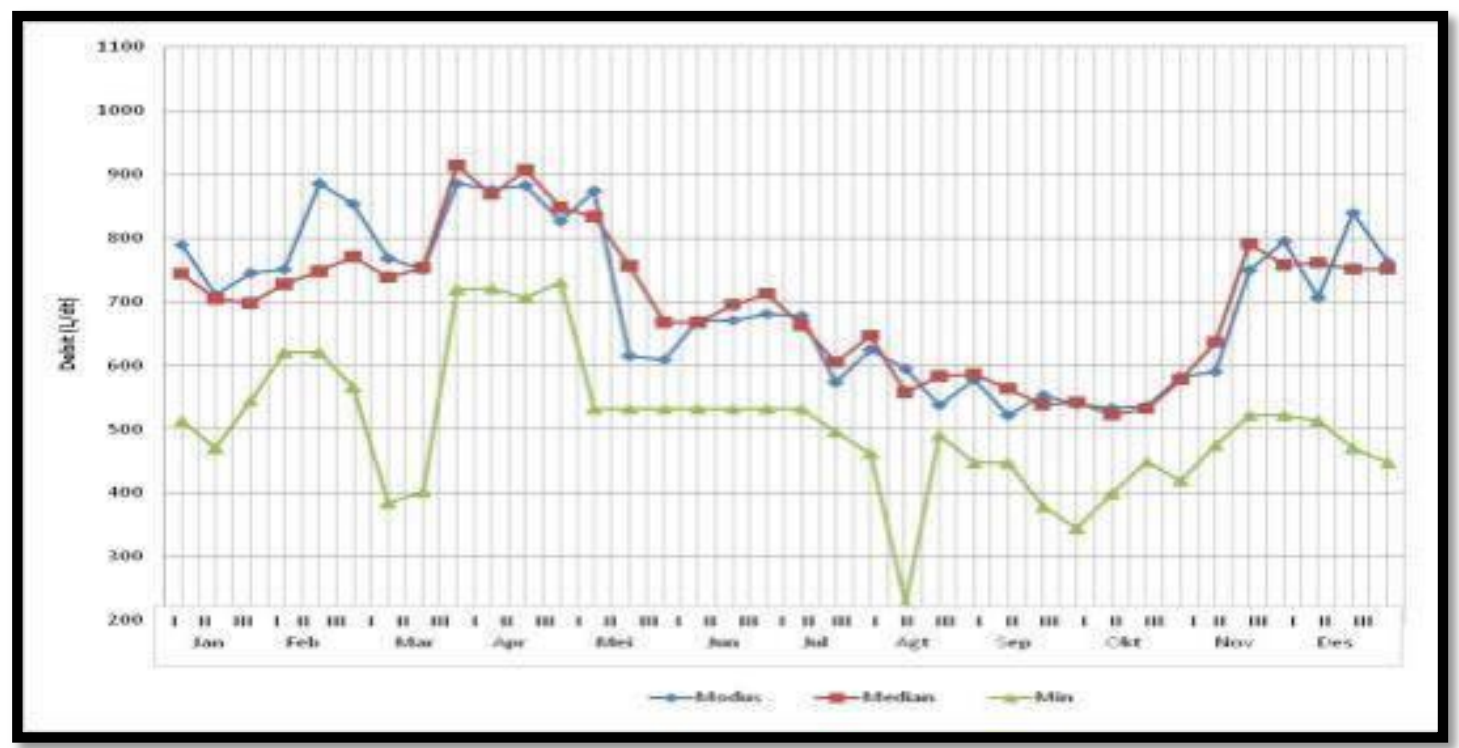

Gambar 4. Grafik Debit Andalan DAM Kedung Putri (Debit minimum, serta Debit Metode Modus dan Median) Sumber : hasil perhitungan 
Pada Gambar 4 terlihat bahwa debit rata-rata modus lebih tinggi dari debit median. Debit andalan dengan menggunakan modus digunakan sebagai debit untuk perhitungan berikutnya. Sebagai acuan apakah debit mencukupi atau tidak.

\section{Evaluasi Pola Tanam dan Intensitas Tanam Kondisi Eksisting}

Evaluasi pola tanam dan intensitas tanam dilakukan pada data yang tersedia yakni pada tahun 2009 - 2014. Hal ini dilakukan guna mengetahui seberapa besar intensitas tanam kondisi eksisting selama lima tahun terkahir guna meningkatkan intesitas tanam berikutnya.

Untuk mendapatkan intensitas tanam dapat dihitung dengan cara menjumlahkan persentase tanaman padi, palawija dan tebu pada tiap musim tanam. Sehingga dapat diketahui apakah persentase intensitas tanam kondisi eksisting dan tanaman yang ditanam sesuai dengan rencana tata tanam. Rerata intensitas tanam padi gadu tidak ijin mencapai mencapai $73,05 \%$.

Tabel. 2. Rekapitulasi Rerata Pencapaian Luas Tanam 2009-2014 Pola Tanam Kondisi Eksisting

\begin{tabular}{|l|l|l|l|l|}
\hline \multirow{2}{*}{ Tahun } & \multicolumn{3}{|l|}{ Intensitas Tanam Rerata $(\%)$} \\
\cline { 2 - 5 } & PADI & Tebu & Palawija & $\begin{array}{l}\text { Padi Gadu } \\
\text { Tidak ijin }\end{array}$ \\
\hline $2009-2010$ & 57,54 & 12,51 & 13,80 & 76,06 \\
\hline $2010-2011$ & 59,94 & 10,08 & 25,37 & 53,56 \\
\hline $2011-2012$ & 60,86 & 8,70 & 12,37 & 78,93 \\
\hline $2012-2013$ & 59,91 & 8,35 & 12,57 & 78,34 \\
\hline $2013-2014$ & 59,91 & 8,29 & 12,57 & 78,34 \\
\hline RERATA MT I & 88,71 & 9,81 & 0,00 & 0,00 \\
\hline RERATA MT II & 90,19 & 9,51 & 0,00 & 0,00 \\
\hline RERATA MT III & 0,00 & 9,13 & 15,34 & 73,05 \\
\hline RERATA TOTAL & 59,63 & 9,49 & 5,11 & 24,35 \\
\hline
\end{tabular}

Sumber : Hasil Analisa

\section{Evaluasi Kebutuhan Air Nyata}

Tabel. 3. Evaluasi Kebutuhan Air Irigasi Nyata Rata Rata Persatuan Luas Tahun 2009-2014

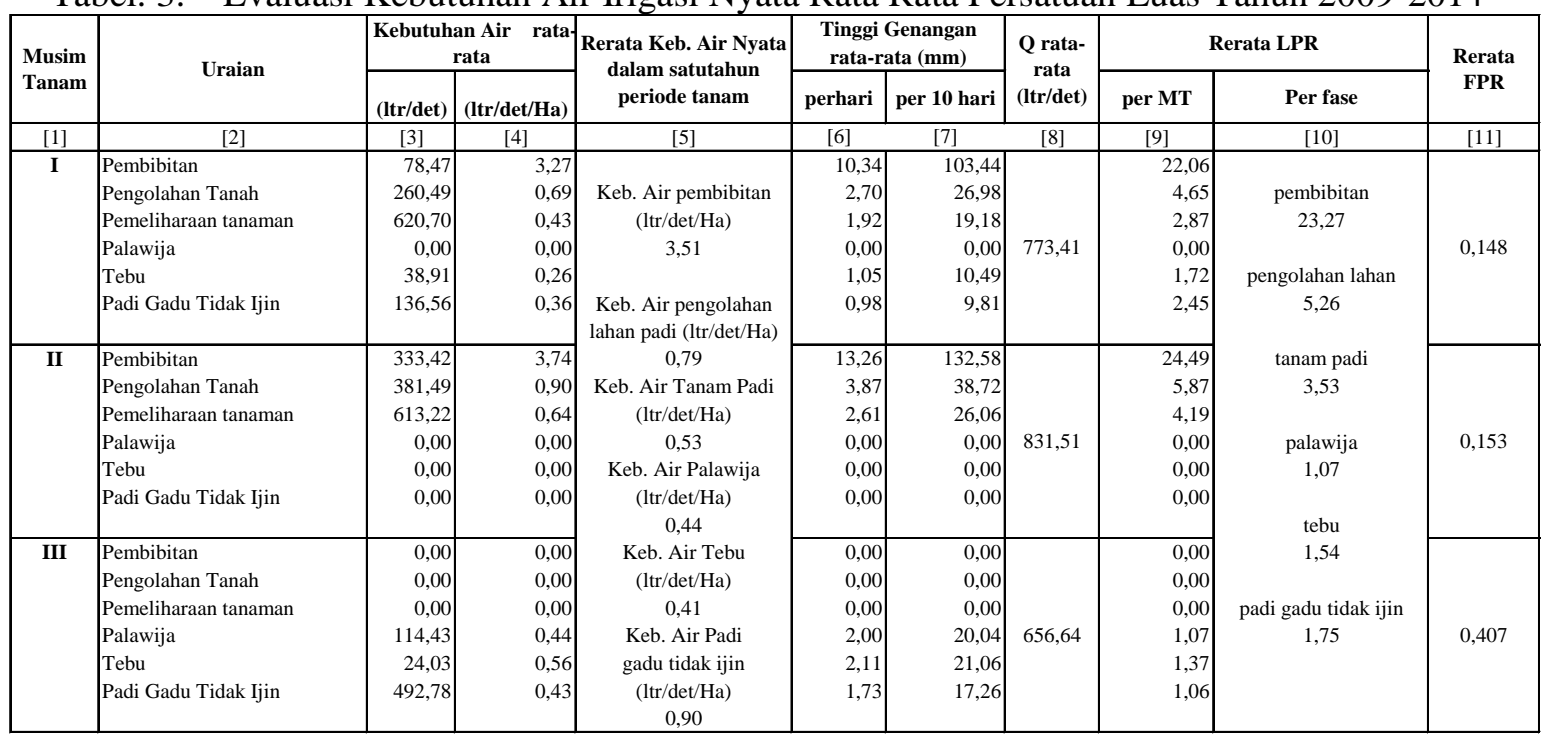

Sumber: Hasil perhitungan

Kebutuhan air irigasi di DI.Kedung Putri seasuai dengan pola tanam dan tanaman yang ditanam.Dimana pola tanam yang dilaksanakan di DI.Kedung Putri adalah Padi + Tebu - Padi + Tebu + Palawija - Tebu + Palawija. Tabel 3. Menjelaskan evaluasi Kebutuhan Air Irigasi 
Nyata Rata Rata Persatuan Luas Tahun 20092014

Dari hasil evaluasi kebutuhan air selama kurun waktu 5 tahun periode tanam (20092014) diperoleh nilai FPR yaitu:

Musim tanam I $=0,148$

Musim tanam II $=0,153$

Musim tanam III $=0,407$

Jika dilihat dari jenis tanah DI. Kedung Putri yaitu grumusol, kondisi air memadai dalam pemberian air. Namun nila dilihat dari Untuk Keperluan Operasional Pembagian Air pada Petak Tersier kurang memadai.

Selain FPR juga diperoleh kriteria koefisien pembanding LPR Tanaman yaitu:

$\begin{array}{ll}\text { Pembibitan } & =23,27 \\ \text { Pengolahan Tanah } & =5,26 \\ \text { Pemeliharaan } & =3,53 \\ \text { Padi Gadu Tak Ijin } & =1,75 \\ \text { Palawija } & =1,07 \\ \text { Tebu Muda } & =1,54\end{array}$

\section{Neraca Air}

Neraca air merupakan perbandingan antara kebutuhan air yang diperlukan dengan debit intake yang tersedia. Dari perhitungan neraca air nantinya akan diketahui bagaimana kondisi air dan dapat dijadikan dalam penga-turan pemberian air irigasi.

Dari hasil analisa neraca air kondisi eksisting Masa Tanam 2009/2014 kebutuhan air irigasi kondisi eksisting dibanding dengan Debit Andalan terdapat giliran dengan jumlah yang cukup banyak yaitu dengan persentase:

\section{9-2010 $=47,22 \%=17 \times$ rotasi}

2010-2011 $=58,33 \%=21 \times$ rotasi

2011-2012 $=58,33 \%=21 \times$ rotasi

2012-2013 $=63,89 \%=23 \times$ rotasi

2013-2014 $=69,44 \%=25 \times$ rotasi

\section{ANALISA POLA TANAM EKSISTING,} RTTG, RENCANA POLA TANAM

Pada analisa tiga pola tanam ini dilakukan dengan 3 metode yaitu metode SRI, SCH, dan gabungan SCH-SRI. Pada pembahasan ini bertujuan untuk mengetahui bagaimana kebutuhan air dari ketiga pola tanam, serta pola anam manakah yang memiliki intensitas padi yg tinggi dengan kebutuhan air paling sedikit apabila menggunakan metode SRI

\section{Pola Tanam Eksisting}

Pola tanam eksisting merupakan pola tanam alternatif pertama dimana luas tanam, jenis tanaman dan waktu tanam sesuai dengan pola tanam kondisi eksisting.

Pada perhitungan pola tanam eksiting ini menggunakan 3 alternatif yaitu:

1. Metode SCH (Stagnant Constan Head)

2. Metode SRI (System of Rice Intensification)

3. Metode gabungan SCH dan SRI.

Dari hasil perhitungan kebutuhan air dengan tiga metode yaitu metode SCH, SRI, dan gabungan pada pola tanam eksisting terlihat bahwa kebutuhan air terhemat pada metode SRI yaitu sbesar 484,84 lt/dt pada bulan November periode III.

Dari total kebutuhan air irigasi diperoleh bahwa metode SRI pada pola tanam eksusting lebih hemat $75,45 \%$, sehingga metode yang paling efektif pada pola tanam eksisting adalah Metode SRI.

Tabel. 4. Rekapitulasi Kebutuhan Air Irigasi Pola Tanam Eksisting

\begin{tabular}{|c|c|c|c|}
\hline \multirow{2}{*}{ Keterangan } & \multicolumn{3}{|c|}{ Kebutuhan Air Irigasi } \\
\cline { 2 - 4 } & Metode SCH & Metode SRI & Metode Gabungan \\
\cline { 3 - 4 } & $1 \mathrm{t} / \mathrm{dt}$ & $1 \mathrm{t} / \mathrm{dt}$ & $1 \mathrm{t} / \mathrm{dt}$ \\
\hline \multirow{2}{*}{$\begin{array}{c}\text { Total Kebutuhan Air 1 tahun } \\
\text { periode tanam }\end{array}$} & \multirow{2}{*}{60193,05} & 13627,53 & 34388,84 \\
\hline Selisih Terhadap SCH & & 46565,52 & 25804,21 \\
\hline Persentase (\%) & & 77,36 & 42,87 \\
\hline
\end{tabular}

Sumber : Hasil Perhitungan

Pada Tabel 5 terlihat bahwa pembagian air dengan gilir paling banyak adalah $80,56 \%$ yaitu sebanyak 29 periode. Sedangkan metode SRI tidak ada pemberian air secara gilir. Itu berarti debit andalan air dapat mencukupi kebutuhan air irigasi.

Tabel. 5. Rekapitulasi persentase Gilir pada Pola Tanam Eksisting

\begin{tabular}{|c|l|c|c|c|c|}
\hline \multirow{4}{*}{ Mnalisa Pola } & \multicolumn{1}{|c|}{ Metode } & $\begin{array}{c}\text { Gilir } \\
\text { Primer }\end{array}$ & $\begin{array}{c}\text { Gilir } \\
\text { Sekunder }\end{array}$ & $\begin{array}{c}\text { Gilir } \\
\text { Tersier }\end{array}$ & Total \\
\cline { 2 - 6 } Tanam Rencana & & 13,89 & 27,78 & 38,89 & 80,56 \\
\cline { 2 - 6 } & Metode SCH & 0,00 & 0,00 & 0,00 & 0,00 \\
\cline { 2 - 7 } & Metode SRI & & & & \\
& $\begin{array}{l}\text { Metode Gabungan SCH } \\
\text { SRI-SRI }\end{array}$ & 0,00 & 27,78 & 13,89 & 41,67 \\
\hline
\end{tabular}

Sumber : Hasil Analisa

\section{Pola Tanam RTTG (Rencana Tata Tanam} Global)

Analisa Rencana Tata Tanam Global untukmengetahui apakah RTTG sudah sesuai dengan ketersediaan air yang ada.

Untuk mengetahui berapa besar kebutuhan air pada RTTG ini dianalisa dengan menggunakan tiga metode yaitu metode Metode SCH (Stagnant Constan Head), SRI (System of Rice Intensification), dan penggabungan antara Metode SCH (Stagnant Constan Head) dan SRI (System of Rice Intensification). 
Tabel. 6. Rekapitulasi Kebutuhan Air Irigasi Pola Tanam RTTG

\begin{tabular}{|c|c|c|c|}
\hline \multirow{3}{*}{ Keterangan } & \multicolumn{3}{|c|}{ Kebutuhan Air Irigasi } \\
\hline & Metode $\mathrm{SCH}$ & Metode SRI & Metode Gabungan \\
\hline & $1 \mathrm{t} / \mathrm{dt}$ & $1 \mathrm{t} / \mathrm{dt}$ & $1 \mathrm{t} / \mathrm{dt}$ \\
\hline $\begin{array}{c}\text { Total Kebutuhan Air } 1 \\
\text { tahun periode tanam }\end{array}$ & \multirow{3}{*}{37371,86} & 11752,90 & 22760,32 \\
\hline Selisih Terhadap SCH & & 25618,96 & 14611,54 \\
\hline Persentase (\%) & & 68,55 & 39,10 \\
\hline
\end{tabular}

Sumber : Hasil Perhitungan

Dari total kebutuhan air irigasi diperoleh bahwa metode SRI pada pola tanam eksisting lebih hemat $68,55 \%$, sehingga metode yang paling efektif pada pola tanam eksisting adalah Metode SRI.

Tabel. 7. Rekapitulasi persentase Gilir pada Pola Tanam RTTG

\begin{tabular}{|c|l|c|c|c|c|}
\hline \multirow{4}{*}{$\begin{array}{c}\text { Analisa } \\
\text { Pola } \\
\text { Tanam }\end{array}$} & Metode & \multicolumn{3}{|c|}{ Persentase Gilir (\%) } \\
\cline { 3 - 6 } & $\begin{array}{c}\text { Gilir } \\
\text { Rencana }\end{array}$ & $\begin{array}{c}\text { Gilir } \\
\text { Sekunder }\end{array}$ & $\begin{array}{c}\text { Gilir } \\
\text { Tersier }\end{array}$ & Total \\
\cline { 2 - 6 } & Metode SCH & 0,00 & 25,00 & 22,22 & 47,22 \\
\cline { 2 - 6 } & Metode SRI & 0,00 & 0,00 & 0,00 & 0,00 \\
\cline { 2 - 6 } & $\begin{array}{l}\text { Metode Gabungan } \\
\text { SCH-SRI-SRI }\end{array}$ & 0,00 & 0,00 & 8,33 & 8,33 \\
\hline
\end{tabular}

Sumber : Hasil Analisa
Pada Tabel 7 terlihat bahwa pembagian air dengan gilir paling banyak adalah $47,22 \%$ yaitu sebanyak 17 periode. Sedangkan metode SRI tidak ada pemberian air secara gilir.

\section{Rencana Tata Tanam}

Tabel. 8. Rekapitulasi Kebutuhan Air Irigasi Pola Tanam Rencana

\begin{tabular}{|c|c|c|c|}
\hline \multirow{2}{*}{ Keterangan } & \multicolumn{3}{|c|}{ Kebutuhan Air Irigasi } \\
\cline { 3 - 4 } & Metode SCH & Metode SRI & Metode Gabungan \\
\cline { 3 - 4 } & $\mathrm{lt} / \mathrm{dt}$ & $\mathrm{lt} / \mathrm{dt}$ & $\mathrm{lt} / \mathrm{dt}$ \\
\hline \multirow{2}{*}{$\begin{array}{c}\text { Total Kebutuhan Air 1 tahun } \\
\text { periode tanam }\end{array}$} & \multirow{2}{*}{61483,81} & 14010,23 & 36873,76 \\
\hline Selisih Terhadap SCH & & 47473,58 & 24610,05 \\
\hline Persentase (\%) & & 77,21 & 40,03 \\
\hline
\end{tabular}

Sumber : hasil perhitungan

Dari hasil perhitungan pada Tabel 8, total kebutuhan air irigasi diperoleh bahwa metode SRI pada pola tanam rencana lebih hemat $70,12 \%$, sehingga metode yang paling efektif pada pola tanam rencana adalah Metode SRI.

Pada Tabel 12 terlihat bahwa pembagian air dengan gilir paling banyak adalah 83,33\% yaitu sebanyak 30 periode dengan metode $\mathrm{SCH}$.

Tabel. 9. Rekapitulasi persentase Gilir pada Pola Tanam Rencana

\begin{tabular}{|c|l|c|c|c|c|}
\hline \multirow{4}{*}{$\begin{array}{c}\text { Analisa } \\
\text { Pola }\end{array}$} & \multicolumn{2}{|c|}{ Metode } & \multicolumn{4}{c|}{ Persentase Gilir (\%) } \\
\cline { 3 - 6 } $\begin{array}{c}\text { Tanam } \\
\text { Rencana }\end{array}$ & Metode SCH & $\begin{array}{c}\text { Gilir } \\
\text { Primer }\end{array}$ & $\begin{array}{c}\text { Gilir } \\
\text { Sekunder }\end{array}$ & Gilir Tersier & Total \\
\cline { 2 - 6 } & Metode SRI & 25,00 & 19,44 & 38,89 & 83,33 \\
\cline { 2 - 6 } & Metode Gabungan SCH-SRI-SRI & 0,00 & 0,00 & 0,00 & 0,00 \\
\hline
\end{tabular}

Sumber : Hasil Analisa

Rekapitulasi Intensitas Tanam Pola Tanam Eksisting, RTTG, Rencana Pola Tanam

Dari ketiga pola tanam yang telah dianalisa, dapat dilihat bawha analisa pola tanam rencana dengan metode SRI adalah alternatif yang paling efektif. Hal tersebut ditunjukkan dengan intensitas tanam padi yang tinggi yaitu $91,49 \%$ pada tiga musim tanam dan kebutuhan air yang paling sedikit yaitu lebih hemat $77,21 \%$ dibandingkan metode $\mathrm{SCH}$.

Tabel. 10. Rekapitulasi Persentase Total Kebutuhan Air dari Tiga Pola Tanam

\begin{tabular}{|l|c|c|c|}
\hline \multicolumn{1}{|c|}{ Persentase } & $\begin{array}{c}\text { Pola Tanam } \\
\text { Eksisting }\end{array}$ & $\begin{array}{c}\text { PolaTanam } \\
\text { Sesuai RTTG }\end{array}$ & $\begin{array}{c}\text { Pola Tanam } \\
\text { Rencana }\end{array}$ \\
\hline $\begin{array}{l}\text { Persentase Total Kebutuhan Air Irigasi } \\
\text { Metode SRI terhadap Metode SCH }\end{array}$ & $75,45 \%$ & $68,55 \%$ & $77,21 \%$ \\
\hline $\begin{array}{l}\text { Persentase Total Kebutuhan Air Irigasi } \\
\text { Metode Gabungan terhadap Metode SCH }\end{array}$ & $38,05 \%$ & $39,10 \%$ & $40,03 \%$ \\
\hline
\end{tabular}


Tabel. 11. Rekapitulasi Intensitas Tanam dengan Pola Tanam Eksisting, Pola Tanam Rencana Tata Tanam Global, Pola Tanam Rencana

\begin{tabular}{|c|c|c|c|c|c|c|c|c|c|c|}
\hline \multirow{3}{*}{$\begin{array}{l}\text { Periode } \\
\text { Musim } \\
\text { Tanam }\end{array}$} & \multicolumn{10}{|c|}{ IntensitasTanam (\%) } \\
\hline & \multicolumn{4}{|c|}{ Pola Tanam Eksisting } & \multicolumn{3}{|c|}{$\begin{array}{c}\text { PolaTanam Sesuai } \\
\text { RTTG } \\
\end{array}$} & \multicolumn{3}{|c|}{ PolaTanam Rencana } \\
\hline & Padi & Palawija & Tebu & Padi Gadu tdk ijin & Padi & Palawija & Tebu & Padi & Palawija & Tebu \\
\hline I & 88,01 & 0,00 & 8,29 & 0 & 91,44 & 0,00 & 8,56 & 91,44 & 0,00 & 8,51 \\
\hline II & 91,71 & 0,00 & 8,29 & 0 & 68,59 & 22,90 & 8,51 & 91,49 & 0,00 & 8,51 \\
\hline III & 0,00 & 12,57 & 8,45 & 78,97 & 18,41 & 73,09 & 8,51 & 91,49 & 0 & 8,51 \\
\hline Total & \multicolumn{4}{|c|}{296,31} & \multicolumn{3}{|c|}{300,00} & \multicolumn{3}{|c|}{300,00} \\
\hline
\end{tabular}

Sumber : Hasil Analisa

Tabel 12 terlihat bahwa pemberian air dengan gilir paling banyak pada pola tanam rencana dengan metode $\mathrm{SCH}$ yaitu sebesar $83,33 \%$. Untuk metode SRI pemberian air secara menerus pada semua pola tanam.Hal tersebut menunjukkan bahwa nilai koefisien $\mathrm{k}$ $>1$ yang berarti debit andalan memenuhi kebutuhan air irigasi. Dari hal tersebut dapat dilihat bahwa Metode SRI cocok untuk kondisi pola tanam rencana.

Tabel. 12. Rekapitulasi Pemberian Air Irigasi dengan Gilir pada 3 Pola Tanam

\begin{tabular}{|c|l|c|c|c|c|}
\hline \multirow{2}{*}{$\begin{array}{c}\text { Pola } \\
\text { Tanam }\end{array}$} & Metode & \multicolumn{4}{|c|}{ Persentase Gilir $(\%)$} \\
\cline { 2 - 6 } & $\begin{array}{c}\text { Gilir } \\
\text { Primer }\end{array}$ & $\begin{array}{c}\text { Gilir } \\
\text { Sekunder }\end{array}$ & $\begin{array}{c}\text { Gilir } \\
\text { Tersier }\end{array}$ & Total \\
\hline \multirow{2}{*}{$\begin{array}{c}\text { Pola } \\
\text { Tanam } \\
\text { Eksisting }\end{array}$} & Metode SCH & 13,89 & 27,78 & 38,89 & 80,56 \\
\cline { 2 - 6 } & Metode SRI & 0,00 & 0,00 & 0,00 & 0,00 \\
\cline { 2 - 6 } & Metode Gabungan SCH-SRI-SRI & 0,00 & 27,78 & 13,89 & 41,67 \\
\hline $\begin{array}{c}\text { Pola } \\
\text { Tanam } \\
\text { RTTG }\end{array}$ & Metode SCH & 0,00 & 25,00 & 22,22 & 47,22 \\
\cline { 2 - 6 } & Metode SRI & 0,00 & 0,00 & 0,00 & 0,00 \\
\hline \multirow{2}{*}{$\begin{array}{c}\text { Pola } \\
\text { Tanam } \\
\text { Rencana }\end{array}$} & Metode Gabungan SCH-SRI-SRI & 0,00 & 0,00 & 8,33 & 8,33 \\
\cline { 2 - 6 } & Metode SRI & 25,00 & 19,44 & 38,89 & 83,33 \\
\cline { 2 - 6 } & Metode Gabungan SCH-SRI-SRI & 0,00 & 0,00 & 0,00 & 0,00 \\
\hline
\end{tabular}

Sumber : Hasil Analisa

\section{Analisa Perhitungan Hasil Produksi Padi}

Pada tabel 13. dapat dilihat bahwa dari hasil perhitungan tiap 1 tahun periode tanam produksi gabah kering lebih unggul bila menggunakan metode SRI yaitu dengan selisih sebesar $78,72 \%$ terhadap metode

Dari tabel 14 dapat diketahui bahwa keuntungan yang diperoleh dari hasil penjualan gabah kering dikurangi biaya operasional penanaman padi lebih tinggi dengan menggunakan metode SRI yaitu pendapatan naik hingga 180,52\% dibanding metode $\mathrm{SCH}$.
Perhitungan Perkiraan penghasilan petani setiap bulan dengan metode SRI Selama 1 Tahun Periode Tanam

- Keuntungan Penjualan Gabah Kering 1 tahun periode tanam $=\mathrm{Rp}$ 135.382.967.583, -

- Keuntungan Penjualan Gabah Kering perbulan

= Keuntungan Penjualan Gabah Kering 1 tahun periode tanam : 12

$=\operatorname{Rp} 135.382 .967 .583,-: 12$

$=\operatorname{Rp} 11.281 .913 .965,-$

- Perkiraan pengahsilan petani perbulan, perhektar 
$=$ Keuntungan Penjualan Gabah Kering perbulan : 1710 ha

$=\operatorname{Rp} 11.281 .913 .965,-: 1710$ ha

$=\operatorname{Rp} 6.597 .610,-$
Sehingga dari perhitungan perkiraan penghasilan petani tersebut, diharapkan kendala kendala dalam penerapan metode SRI dapat teratasi

Tabel. 13. Biaya Tanam Padi per Musim Tanam per Hektar

\begin{tabular}{|c|c|c|c|c|}
\hline \multirow{2}{*}{ URAIAN } & \multicolumn{2}{|r|}{$\mathrm{SCH}$} & \multicolumn{2}{|r|}{ SRI } \\
\hline & Jumlah & $(\mathrm{Rp})$ & Jumlah & $(\mathrm{Rp})$ \\
\hline Benih (kg) & 30 & $187.131,58$ & 19,88 & $119.515,15$ \\
\hline \multicolumn{5}{|l|}{ Pupuk } \\
\hline Pupuk Organik (kg) & & & 2303,0 & $2.993 .900,00$ \\
\hline Pupuk Urea $(\mathrm{kg})$ & 153,29 & $597.831,00$ & 3900 & \\
\hline Pupuk SP36 (kg) & 65,79 & $236.844,00$ & 3900 & \\
\hline$\overline{\mathrm{KCL}}(\mathrm{kg})$ & 54,61 & $212.979,00$ & - & - \\
\hline Phoska (kg) & 40,79 & $159.081,00$ & 3900 & \\
\hline \multicolumn{5}{|l|}{ Pestisida } \\
\hline Pestisida Organik (lt) & - & - & 2,06 & $226.600,00$ \\
\hline Pestisida Kimia (lt) & 7,33 & 1172067 & - & \\
\hline \multicolumn{5}{|l|}{ Biaya Tenaga Kerja } \\
\hline a. Pengolahan Lahan & & $1.000 .000,00$ & & $1.000 .000,00$ \\
\hline b. Penanaman dan Penyulaman & & $900.000,00$ & & $889.962,83$ \\
\hline c. Pemeliharaan & & $800.000,00$ & & $585.478,47$ \\
\hline d. Pemupukan & & $300.000,00$ & & $283.450,23$ \\
\hline e. Pengendalian OPT & & $300.000,00$ & & $95.848,56$ \\
\hline f. Pemanenan, Perontokan, dan Pengangkutan & & $1.300 .000,00$ & & $1.914 .802,74$ \\
\hline Jasa Pertanian & & $1.600 .000,00$ & & $1.600 .000,00$ \\
\hline Sewa Alat & & $300.000,00$ & & $300.000,00$ \\
\hline Sewa Lahan & & $3.800 .000,00$ & & $3.800 .000,00$ \\
\hline bahan Bakar & & $100.000,00$ & & $100.000,00$ \\
\hline Lainnya & & $400.000,00$ & & $400.000,00$ \\
\hline Jumlah & & $13.365 .933,58$ & & $14.309 .557,98$ \\
\hline Total Biaya 1 Tahun Periode Tanam & & $567.239 .265,40$ & & $408.032 .414,62$ \\
\hline
\end{tabular}

Sumber : Hasil Perhitungan

Tabel. 14. Pendapatan Yang Diperoleh dari Metode SRI (System of Rice Intensification) dan SCH (Stagnant Constant Head)

\begin{tabular}{|l|c|c|c|}
\hline \multicolumn{1}{|c|}{ Uraian } & SCH & SRI & Persentase (\%) \\
\hline Total Biaya Produksi (Rp) & $68.567 .239 .265,40$ & $73.408 .032 .414,62$ & 7,06 \\
\hline Total hasil penjualan Gabah Kering (Rp) & $116.828 .055 .000,00$ & $208.791 .000 .000,00$ & 78,72 \\
\hline Total hasil Penjualan beras (Rp) & $189.450 .900 .000,00$ & $711.018 .000 .000,00$ & 275,30 \\
\hline Keuntungan Penjualan Gabah Kering (Rp) & $48.260 .815 .734,60$ & $135.382 .967 .585,38$ & 180,52 \\
\hline Keuntungan Penjualan Beras (Rp) & $120.883 .660 .734,60$ & $637.609 .967 .585,38$ & 427,46 \\
\hline
\end{tabular}

Sumber : Hasil Perhitungan

\section{KESIMPULAN DAN SARAN}

\section{Kesimpulan}

1. Intensitas tanam padi kondisi eksisting

Dari hasil evaluasi intensitas tanam selama 5 tahun terakhir (2009-2014) periode tanam DI. Kedung Putri dapat diketahui bahwa intensitas tanam rencana sebesar $300 \%$, sedangkan realisasi sebesar $296,52 \%$.

2. Jumlah penggunaan air irigasi

Dari hasil analisa 3 pola tanam dan 3 metode yaitu metode SCH, SRI serta Gabungan SCH-SRI dapat disimpulkan bahwa metode yang paling efektif untuk pemberian kebutuhan air adalah metode SRI. Hal tersebut ditunjukkan dengan 
intensitas tanam padi yang tinggi namun kebutuhan air yang sedikit yaitu $68,55 \%$ $77,21 \%$ lebih hemat dari metode $\mathrm{SCH}$. Pembagian air secara rotasi dengan metode SRI tidak ada, sedangkan metode SCH mencapai $83,33 \%$ yaitu 30 periode.

3. Hasil Produksi Padi dan Hasil Pendapatan

Dapat disimpulkan bahwa dari hasil perhitungan tiap 1 tahun periode tanam produksi gabah kering lebih unggul bila menggunakan metode SRI yaitu dengan selisih sebesar 24854,85 ton dengan persentase 78,72\% terhadap metode SCH.

Dari hasil pembahasan dapat diketahui bahwa asumsi pendapatan yang diperoleh petani adalah $\mathrm{Rp}$ 6.597.610,00 perbulan perhektar.

\section{Saran}

1. Diharapkan pada penelitian berikutnya agar melakukan beberapa hal berikut:

a. penelitian lebih lanjut terhadap produktivitas padi dengan menanam padi di suatu lahan dengan menggunakan metode SRI.

b. Perlu adanya pengukuran tinggi genangan setiap 10 hari sekali untuk memperoleh data yang lebih akurat.

c. Perlu dilakukan analisa optimasi terhadap pola tanam agar mendapatkan pola tanam yang paling efektif sesuai debit yang tersedia.

\section{DAFTAR PUSTAKA}

Anonim. 1977. Pedoman Bercocok Tanam Padi, Palawija,Sayursayuran. BadanPengendali Bimas Departemen Pertanian. Jakarta.
Anonim. 1986. Kriteria Perencanaan Jaringan Irigasi KP-01, Kriteria Perencanaan Penunjang . Ditjen. Pengairan Dep. PU Galang Persada. Bandung.

Budi, Ariani. 2007. Irigasi Sistem SRI Sebagai Solusi Kelangkaan Air dan Peningkatan Produksi Padi di Daerah Irigasi Jatiluhur. Jurnal Teknik Volume 6 no 2 UNJANI.

Mutakin, Jenal.Budidaya Dan Keunggulan Padi Organik Metode Sri (System Of Rice Intensification). Diakses pada tanggal 26 Maret 2015, http://web.mb.ipb.ac.id/uploads/

docPdf/BUDIDAYA_DAN_KEUNGGU LAN_PADI_ORGANIK_METO DE_SRI_(System_Rice_c2e $48 \mathrm{~d} 8$ 9fc246be072afcd9069096f69.pdf.

Purba, J. H. 2011. Kebutuhan dan Cara Pemberian Air Irigasi untuk Tanaman padi Sawah (Oryza sativa L.).WIDYATECH Jurnal Sains dan Teknologi Vol. 10 No. 3.

Rohmat, Dede. 2007. Kajian Aspek Pemberian Air dan Mekanisme Penyediaan Hara pada Budidaya Tanaman Padi - Pola SRI.Bandung. UPI.

Sosrodarsono, S. dan Takeda, K. 1980.Hidrologi untuk Pengairan.PT. Pradnya Paramitha. Jakarta. 